\title{
FORMAÇÃO E TREINAMENTO DE PROFESSORES PARA EDUCAÇÃO INFANTIL
}

\section{FORMATION ETA PPRENTISSAGE DE MAITRES D'ÉDUCATION INFANTILE}

DIDONET, V. Formação e Treinamento de Professores para a Educação Infantil. Rev. Bras. Cresc. Des. Hum. 111(1): São Paulo, 1993.

\section{RESUMO}

Como ocorre nas políticas de assistência social, na área da formação de professores de educação infantil há um vácuo entre a legislação e a prática.

Para suprir a falta de habilitação especifica, não encontrada nas escolas normais, surgem os cursos de treinamento, oferecendo uma preparação prática e imediata aos profissionais que aluam na educação pré-escolar. Atualmente, há cursos de atualização disponíveis em quase todo o País. Em Belém, faz-se uma experiência inovadora na formação de professores.

\section{RÉSUMÉ}

I1 existe un vide entre la législation et la pratique dans te domaine de la formation des mestres d'éducation infantile, comme dans toutes lãs politiques d'assistance sociale.

Afin de combler te déficit de formation spécifique, non retrouvée dans les écoles normales, sont apparus les cours d'apprentissage, qui offrent une préparation pratique et immediate aux professionnel sconcernés à l'éducation pré-scolaire. Actuellement, il existent des cours d'actualisation, disponibles dans pratiquement tout le pays. A Belém a lieu une expérience innovatrice de ce type.

Apresento neste texto um breve resumo de como é feita a formação dos professores de educação infantil no Brasil. Aprática está ainda distante do que a legislação propõe, e mesmo do que pretendem os Projetos de Diretrizes e Bases da Educação Nacional, em tramitação no Congresso Nacional. O Projeto de lei n ${ }^{\circ} 1.258 / 88$, da Camara dos Deputados, propõe a formação em nível médio, com duração de quatro anos (Escola Normal), sendo possível também a formação em nível superior. O Projeto de lei ${ }^{\circ}$ 67/92, do Senado Federal, quer a formação, preferencialmente, de ní- vel superior em institutos superiores de educação. Não acho que a lei proponha um patamar ideal de formação, inatingivel na prática: ela simplesmente estabelece aquilo que deveria ser honestamente buscado pela adm nistração educacional.

Uma explicação para a existência de muitos professores atuando no sistema de ensino, sem a qualificação exigida por lei, são os salários baixos que eles recebem. O salário pago aos professores não atrai e não conserva os que têm melhor nível. Também não é um bomestimulo para os

1 Assessor Parlamentar. Assessoria Legislativa, anexo III, Gab. 60. Câmara dos Deputados - Brasília/DF - Brasil - Fone: (061) 318-6707. 
jovens talentosos entrarem nos cursos de formação do magistério

A educação infantil expandiu-se a taxas acelaradas nos últimos anos (média de 10\% ao ano), absorvendo um número cada vez maior de professores formados pelas escolas normais. Mas essas escolas não criam opções para habilitações específicas para 0 magistério na préescola. Daí a grande demanda e a necessidade crescente dos "cursos de treinamento", que dão uma preparação prática e imediata para os que querem trabalhar na pré-escola. Os sistemas de ensino e a Organização Mundial para a Educação Pré-Escolar (OMEP) of erecem cursos de atualização e aperfeiçoamento duraúte o ano todo, em várias regiões do País.

\section{Modelo de formação}

A criança é um ser de relações: sua vida se desenvolve na convivência, entre a depedência e a autonomia. Da circunst $\sim$ ncia ffsica e social da qual faz parte e com a qual se relaciona, recebe os meios para desenvolver-se e construir sua vida. Da forma como os adultos se relacionam com ela vai depender, em grande parte, que a criança se torne autonoma ou permaneça heterônoma, que tenha coragem de enfrentar os problemas ou seja dominada pela timidez. Isso também vai determmar que seja criativa ou pró ira ocultar-se na rotina e na repetição daquilo que Ihe dá segurança.

Ao deixar sua casa por quatro ou mais horas diárias para frequentar um centro pré-escolar, a criança entra em um ambiente que amplia seu horizonte de relações sociais. Passa a conhecer outras crianças, com as quais estabelece laços de amizade, trabalha e brinca, divide materiais de uso comum e coopera em projetos coletivos. Os adultos que com ela se relacionam nesse centro, e que não são seus parentes, usam uma linguagem diferente e Ihe apresentam desafios. Manifestam expectativas e oferecem apoios diversos daqueles que ela recebe em casa.

Mas há necessidade de se manter no centro de educação infantil determinados elementos familiares, de natureza afetiva, como o aconchego, o colo, o carinho. Isso não significa que o centro pré-escolar seja uma simples continuação do lar, um substituto da familia. Jardim de infancia/ pré-escola e casa de família são coisas distintas. E o professor (ou educador) pré-escolar não é um tio, mas um profissional a quem é confiada a tarefa de apoiar e estimular o desenvolvimento e a aprendizagem da criança com base nos conhecimentos científicos. Para tanto, ele utiliza os meios mais adequados que as ciências da educação Ihe of erecem.
O caráter profissional do trabalho do professor (educador) não pode ser minimizado. Ao contrário, ele deve ser um especialista para entender a criança, conhecer os processos bio-psicosociais pelos quais ela se desenvolve e as formas ou metodologias mais apropriadas para alimentar tais processos.

A formação do magistério tem-se beneficiado nos últimos anos, das mais recentes descobertas da psicologia, psicanálise, antropologia e outros ramos do conhecimento. A literatura especializada e mesmo publicações de caráter popular já trazem o conhecimento sobre os processos de desenvolvimento infantil, a construção da inteligência, a formação da personalidade.

No entanto, nem todos os professores têm acesso a tais fontes, seja porque o salário não permite a compra de livros e revistas especializadas, ou simplesmente porque não se reciclararrt ou então vivem afastados dos grandes centros. A experiência pedagógica na pré-escola está criando constantemente conhecimentos e uma prática cada vez mais consciente e adequada para apoiar a criança em seu desenvolvimento. Ampliar os espaços de intercomunicações dessa experiência entre os professores é criar oportunidades para todos se beneficiarem.

O ensino médio é o nível que forma os professores para a pré-escola e para as quatro primeiras séries do ensino fundamental. O curso, chamado de Curso de Magistério, é oferecido pelas escolas normais. $\mathrm{O}$ curso superior forma os professores para lecionar da $\wedge 5 \mathrm{u}$ à Bá séries e no ensino médio, além dos técnicos de ensino (supervisores, administradores, orientadores educacionais, planejadores de ensino).

As instituições de ensino superior podem of erecer cursos de especialização para os professores de educação especial, de alfabetização de adultos, educação pré-escolar, etc. Mas os formados por esses cursos geralmente trabalham nas estruturas intermediárias dos sistemas de ensino e não diretamente com as crianças. Quando não há professores formados segundo esses níveis, são aceitos outros com grau de formação mais baixo.

Constata-se que 63\% dos professores préescolares têm formação de nível médio na área de magistério. Porém, na maior parte dos casos, a formação não é específica para a atuação na educação infantil. São conhecidas as deficiências do curso de formação do magistério para a pré-escola e para o ensino fundamental no Brasil. Avaliações têm indicado que o curso hipertrofia os aspectos instrumentais em detrimento do conteúdo. Dentre os cursos de nível médio, 0 demagistério é considerado 0 mais fraco emconteúdo cien ílïco. E nem os instrumentais são tratados adequadamente. 


\section{Situação prática}

O quadro de magistério da pré-escola conta com 155 mil professores, que atendem a 3,5 milhões de crianças (estimativas para 0 ano de 1990), 0 que dá uma média de 24,5 crianças por professor.

\begin{tabular}{lc} 
Curso de formação do professor & percentual \\
\hline Primário incompleto & 4,94 \\
Primário completo & 5,45 \\
Médio (magistério) incompleto & 5,75 \\
Médio (magistério) completo & 59,91 \\
Médio (não-magistério) & 3,57 \\
Superior (magistério) incompleto & 5,47 \\
Superior (magistério) completo & 13,75 \\
Superior (não magistério) & 1,13 \\
\hline
\end{tabular}

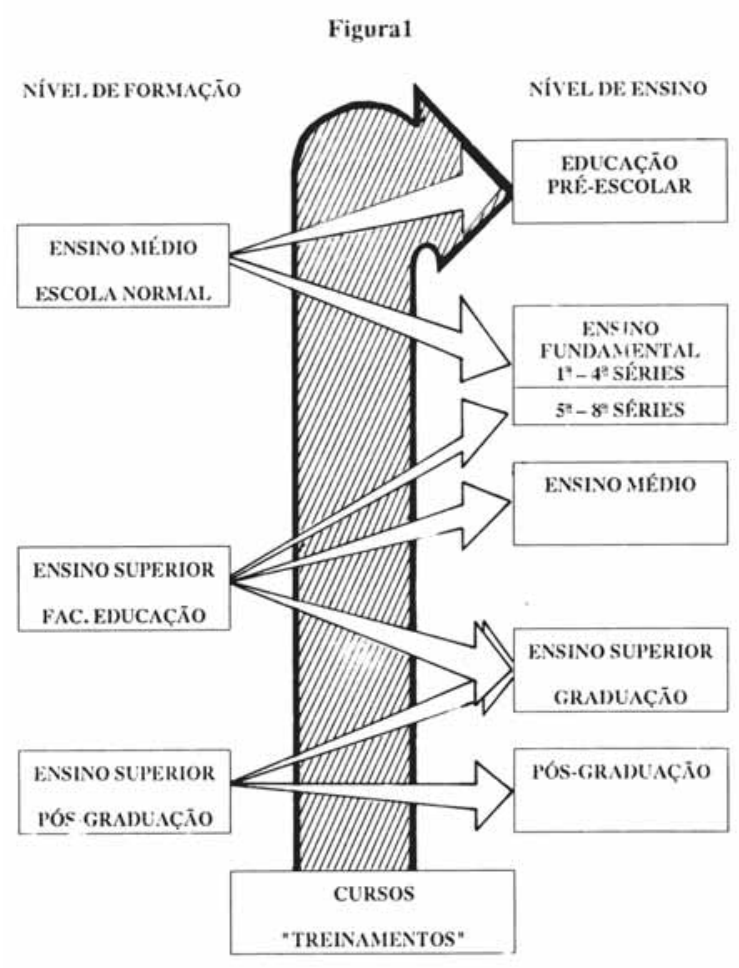

\section{Treinamcntos}

Em todo o País, são oferecidos muitos cursos, tanto em período de aulas quanto nas férias escolares. Eles atualizam, aperfeiçoam e aprofundam a prática e o conhecimento dos professores pré-escolares. São promovidos pelas Secretarias de Educação (de caráter público e gratuito), pela OMEP c por outras organizações não governamentais (ONG). Além disso, há congressos e seminários, estaduais c nacionais, a cada ano, atraindo milhares de professores e estudantes.

É notório o interesse dos professores préescolares por cursos, oficinas e congressos. Participam intensamente, procuram aprender o máximo, estabelecem vínculos para intercâmbio de experiências e materiais com colegas. Esses cursos são a principal fonte de ideias para os professores da pré-escola renovarem seu programa de trabalho e incursionarem por novas formas de fazer a pedagogia pré-escolar

No entanto, por serem cursos breves (24 ou 48 horas), geralmente não reservam tempo para estudo teórico, ficando nos aspectos práticos (metodologia e técnicas) e são voltados para um assunto específico de interesse no momento. Ex.: psicomotricidade, música, atividades físicas na préescola, aprendizagem da leitura e da escrita, etc.

Assim, o professor volta renovado ao convívio com as crianças, mas lhe falta maior embasamento teórico, que lhe permita ser, inovador e criador de uma nova prática pedagógica. Ou seja, tais recursos contribuem muito pouco para a autonomia do professor na busca de maior conhecimento e de uma prática mais consciente e critica.

A OMEP/BRASIL, em alguns estados (Mato Grosso, Rio Grande do Sul) tem oferecido cursos mais longos (180 a 240 horas), possibilitando um estudo aprofundado de aspectos téoricocientíficos da educação infantil c uma abrangência maior dos assuntos. O Ministério da Educação e a Fundação Roberto Marinho produziram um programa de capacitação de professores da préescolapor multimeios. O curso consta de três eixos: programas de televisão (vídeo), livro-texto e estudo/debate em grupo.

\section{Televisão e livro}

Os objetivos da utilização da midia (televisão): alcançar simultaneamente um grande número de professores em todo o território nacional, utilizando-se de redes de televisão (comercial e educativa); of erecer um curso de conteúdo profundo e dinâmico, contendo os conhecimentos mais atualizados e algumas experiências expressivas da pré-escola no Pais. O conteúdo é o seguinte:

Temas gerais (visão panoramica do campo de trabalho do proiessor): infância, situação da pré-escola, a criança de três a sete anos, socialização. Temas específicos (trabalho com a criança- objetos sociais do conhecimento): jogos e brinquedos na pré-escola, expressão ar- 
tística e ciências, além de aritmética, língua portuguesa e história. Há temas específicos também sobre a atuação do professor e sua relação com os alunos.

O livro-texto tem uma função própria e insubstituível, diferentes dos videos: estudo e reflexão, releitura e manuseio diário, sendo utilizado individualmente e em grupo; apresentação de pequenos textos de bons autores sobre os temas da educação infantil; uso da iconografia como Instrumento de comunicação e informação complementar ao texto.
O curso deve ser feito em grupo: seis a oito professores assistem ao video ou ao programa de televisão, leêm o capitulo correspondente no livro e debatem o assunto, procurando fazer referências às suas práticas. Essa ordem pode variarconforme o interesse do grupo. Ao final da discussão, é elaborado um relatório, contendo a sintese dos debates, as questões e as dúvidas que persistem, incluindo eventuais solicitações de leituras adicionais. O relatório é encaminhado à coordenação municipal ou estadual, para resposta, acompanhamento e informações sobre o andamento do curso.

Figura 1

\section{Esquema de concepção do curso}
(1)

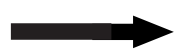
(3)

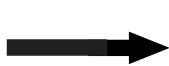
(4)

TEORIA E PRÁTICA
apresentadas nos vídeos
e no Livro-Texto
NOVA PRÁTICA
modificada, refletida à luz da teoria e da experiência debatidas com os colegas

\author{
TEORIA construida pelo professor à \\ luzda teoria e da prática vistas no \\ curso e da reflexão sobre sua nova
} prática

PRATICA
atual do professor
Os programas de TV estão sendo veiculados por rede nacional, uma vez por semana; em alguns estados, pelas TVs educativas (governamentais). Foram distribuidor pelo Ministério da Educação (MEC) dois mil conjuntos de fitas VHS com o programa completo, que estão sendo usados em centros de treinamentos, video-escolas e outros locais que se prestam para realizar o curso.

Os professores da pré-escola pública já receberam 50 mil exemplares do livro texto, mas há solicitações para mais 30 mil exemplares, além de ires mil cópias do video. Não foi montado nenhum programa de avaliação nacional. O MEC está recebendo muitas castas das secretarias de educação e outras instituições, com comentários sobre o curso. Todas as cartas elogiam o programa, afirmando que os professores estão gostando muito e tendo bom proveito.

\section{Experiência inovadora}

Foi criado, em 1990, em Belém, o instituto Superior dc Educação do Pará ( ISEP), para a formação de profissionais de educação básica, da prc-escola à $4 \wedge 4$ série do ensino fundamental ( 0 -10 anos). Tendo como pressuposto que o inicio do processo educacional deveria estar confiado a profissionais de alta qualificação, e que a educação inicial deve ser entendida de modo integrado, organizou-se uma instituição para of erecer cursos capazes de formar profissionais em nivel superior.

Profissionais que entendam o contexto e os processos formativos da criança, desde o nascimento até os 10 anos de idade (antes do inicio da adolescência). São as seguintes as características principais desse curso:

Tempo integral dos alunos para o curso; unidade curricular entre teoria e prática (toda prática deve ter elaboração teórica); unidade curricular entre pesquisa e ensino; elaboração de trabalhos pelos alunos (estudo, leitura, pesquisas, com predomínio da produção individual sobre trabalhos em grupo); formação académica (disciplinas tradicionais) combinada com formação política (compreensão da cidadania da criança, participação critica e consciente na vida social e política); formação abrangente (para faixa de O 10 anos) predominante sobre as especializações (pré-escolar: 0 - 6 anos, $1^{\mathrm{a}}$ a $4^{\mathrm{a}}$ séries).

Com três anos de exercício, a experiência demonstra necessidade de modificação de algumas características do modelo, mas indica, também, que desse modelo poderá surgir uma nova forma de atuação do magistério na educação básica. Há muito interesse pela pesquisa, pela "recriação" e criação do conhecimento e, consequentemente, uma atitude critica permanente diante dos conteúdos e da forma tradicional e rotineira de ensinar. 